\title{
An Empirical Analysis of the Effects of the Stock Index Futures on the Spot Market Volatility of China
}

\author{
Hui-Chun $\mathrm{CHE}^{1, \mathrm{a}}$, Fang $\mathrm{CAO}^{1, \mathrm{~b},{ }^{*}}$ \\ ${ }^{1}$ Beijing Wuzi University, Beijing, China \\ achehuichun@126.com, ${ }^{\mathrm{b}}$ caofang137@126.com \\ ${ }^{*}$ Corresponding author
}

Keywords: stock index futures, the spot market, volatility.

\begin{abstract}
The paper studies the effects of the stock index futures on the spot market volatility of China, through GARCH model, using HS300 stock index futures and the HS300 index as the research object. The empirical results show that the HS300 stock index futures has weakened the spot market volatility in spite of its very small; In addition, the introduction of HS300 stock index futures accelerate the transmission of the spot market information, showing that stock index future develop the function of price discovery.
\end{abstract}

\section{Introduction}

The first stock index futures contract officially listed on exchanges in the United States, Kansas, on February 24, 1982, then it has become an important tool to avoid the risks and promote the stability development of the spot market. China financial futures exchange (CFFE) issued the HS300 index futures simulation transaction price index On October 30, 2006, then officially launched the HS300 index futures On April 16, 2010. The introduction of stock index futures not only improves the structure of China's securities market, but also has a profound impact on promoting the healthy development of China's securities market. Since then, the relation between the introduction of stock index futures market and the spot market volatility has become a controversy topic, which is the study in this paper.

\section{Literature review}

A variety of Scholars at home and abroad study the effects different stock index futures on the volatility of different the spot market. Bologna (2002) analyze the volatility of the Indian stock market based on the GARCH model, and the results show that the launch of stock index futures decreases the volatility of stock cash market; Li Zhuo (2007) carried on the empirical analysis in our country Taiwan area about the impact of stock index futures on the spot, which is showing that the introduction of stock index futures reduce the volatility of the spot market in Taiwan; Huang Wei, Liu Zaihua (2007) by studying the stock index futures influenced the volatility of NIFTY in Indian stock market concluded that: the introduction of NIFTY index futures effectively reduced the volatility of the Indian stock market.

\section{Model specification and data processing}

Model specification

$\operatorname{GARCH}(p, q)$ model is as follows: 


$$
\sigma_{t}^{2}=a_{0}+a_{1} \mu_{t-1}^{2}+\ldots . .+a_{i} \mu_{t-1}^{2}+\ldots . .+a_{q} \mu_{t-q}^{2}+\beta_{1} \sigma_{t-1}^{2}+\ldots . .+\beta_{j} \sigma_{t-j}^{2}+\ldots . .+\beta_{p} \sigma_{t-p}^{2} .
$$

Wherein $\mathrm{p}, \mathrm{q}$ is a positive integer; $\mathrm{a}_{0}>0, \mathrm{a}_{\mathrm{i}} \geq 0, \mathrm{vi}=1,2, \ldots \ldots, \mathrm{q} ; \beta_{\mathrm{j}} \geq 0, \mathrm{j}=1,2, \ldots \ldots, \mathrm{p}$; GARCH model uses four parameters to describe its volatility, which $a_{0}$ represents uncertainty in the original system, $a_{i}$ says the impact of new information on market volatility, and $\beta_{j}$ characterizes the impact of old information on the market volatility. In this model, the greater the value of $a_{i}$, the better the speed and quality of information transmission, and the greater the value of $\beta_{\mathrm{j}}$, suggesting the influence of volatility interference factor more durable and the poorer the speed and quality of information transmission.

In addition, when the articles on total sample modeling, the GARCH model is introduced a virtual variable $D$, which set $D=0$ before HS300 index futures issued and set $D=1$ after HS300 index futures issued. So the conditional variance equation of GARCH model, adding the virtual variables, can be written as:

$$
\sigma_{t}^{2}=a_{0}+a_{1} \mu_{t-1}^{2}+\ldots . .+a_{i} \mu_{t-1}^{2}+\ldots . .+a_{q} \mu_{t-q}^{2}+\beta_{1} \sigma_{t-1}^{2}+\ldots . .+\beta_{j} \sigma_{t-j}^{2}+\ldots \ldots+\beta_{p} \sigma_{t-p}^{2}+\varphi D .
$$

If $\varphi>0$, the introduction of stock index futures increases the volatility of the stock market; If $\varphi<$ 0 , it reduces the volatility of the stock market, and if $\varphi=0$, the stock index futures has no effect on the volatility of the stock market.

\section{Data selection and statistical description}

\section{Data selection}

The paper selects daily closing price of HS300 index as data, and the reason of choosing it is that it reflects most of the market behavior and more persuasive. All data come from the netease finance. In order to compare the influence on the spot market volatility before and after the stock index futures introduced, data is divided into two subintervals, which are the HS300 index of daily closing price $\left(\mathrm{I}_{\mathrm{t}}\right.$ )before the HS300 index futures introduced ( April 10, 2007 - April 15, 2010) and after the HS300 index futures introduced (April 16, 2010-March 15,2013). And the total of the data are 1474.

In paper, R, R1, R2 are respectively used to present the return of the total samples, before the introduction of HS300 index futures, and after the introduction of HS300 index futures. In addition, the paper uses the log-return first order difference as day returns, so the calculation formula is:

$$
\mathrm{Rt}=\mathrm{Ln}(\mathrm{It})-\mathrm{Ln}(\mathrm{It}-1)
$$

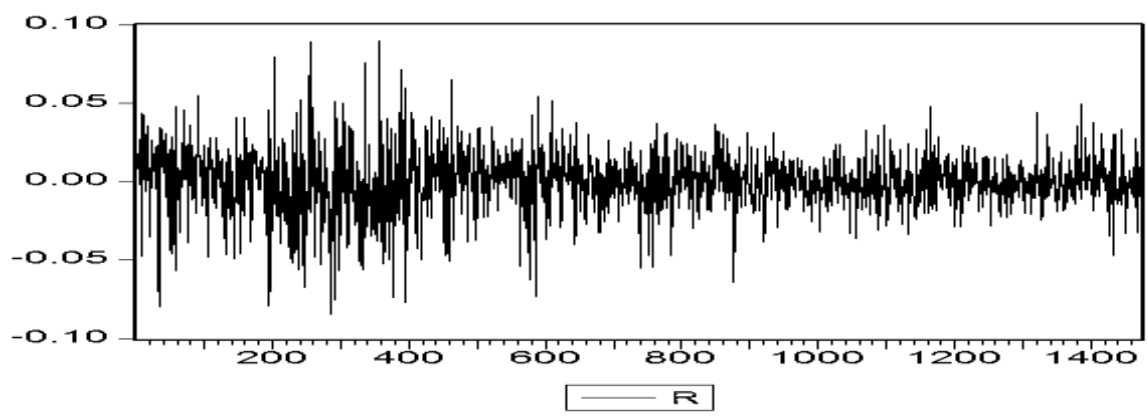

Figure 1 the HS300 index day return line chart 


\section{Descriptive statistics}

Table 1 the result of descriptive statistics

\begin{tabular}{|c|c|c|c|c|c|c|}
\hline $\begin{array}{c}\text { The return of } \\
\text { sample interval }\end{array}$ & Mean & $\begin{array}{l}\text { Standard } \\
\text { deviation }\end{array}$ & skewness & Kurtosis & $\begin{array}{c}\text { J - B } \\
\text { statistics }\end{array}$ & Q(12) \\
\hline R & -0.000144 & 0.020074 & -0.287 & 5.15 & 304.078 & 22.286 \\
\hline R1 & 0.000131 & 0.024599 & -.0308 & 4.08 & 47.210 & 15.337 \\
\hline R2 & -0.000404 & 0.014199 & -0.138 & 4.62 & 82.865 & 16.969 \\
\hline
\end{tabular}

In the each sample interval, the return of HS300 index of kurtosis is greater than the normal distribution (3) and there is a certain degree of skewed to the left, showing that the return of HS300 index presents a peak and fat tail. In addition, $\mathrm{J}$ - B statistic test also illustrates that the return does not obey the normal distribution, and the Q (12) statistic test presents that the yield serious autocorrelation, showing a greater volatility clustering and heteroscedasticity, which can describe by GARCH model.

\section{The empirical test and analysis}

The article uses Eviews3.0 to analyze the return of HS300 index. First of all, each sample interval of the return has been tested by stationary test. If the variable is smooth, then the influence of the stock index futures on the spot market volatility should be analyzed by establishing the optimal GARCH model.

\section{Stationary Test}

In order to prevent false regression problems, ADF test is carried out on each of the sample interval. For a time series, When the statistics is less than the critical value of a given significance level, the original hypothesis, the sequence is non-stationary, otherwise, the time series is stationary.

Table 2, the result of ADF test

\begin{tabular}{|c|c|c|c|c|}
\hline & ADF & $1 \%$ & $5 \%$ & $10 \%$ \\
\hline R & -16.41119 & -3.9695 & -3.4154 & -3.1296 \\
\hline R1 & -11.47970 & -3.9753 & -3.4182 & -3.1312 \\
\hline R2 & -11.86591 & -3.9753 & -3.4182 & -3.1312 \\
\hline
\end{tabular}

According to the test results of table 2, three sample intervals statistic are less than the critical value of significance level at $1 \%$, suggesting that all the time series have unit root, which is namely all the time series are smooth.

\section{Establish and analysis the GARCH model}

\section{The selection of the order of $\operatorname{GARCH}(p, q)$ model}

The paper introduces the AIC and SC criterion in order to acquire the $\operatorname{GARCH}(p, q)$ model order exactly. Comparison table 3 , table 4 , table 5 can learn that each of the sample interval's GARCH $(1,1)$ of the AIC and SC are smaller, which is able to fully capture the volatility clustering phenomenon. In addition, the $\operatorname{GARCH}(1,1)$ model has the characteristics of simple, accurate, and 
better fitting effect, so in this article, GARCH $(1,1)$ model is used for research.

Table 3, the selection order of the total sample

\begin{tabular}{|l|l|l|l|}
\hline & AIC & SC & DW \\
\hline GARCH $(1,1)$ & -5.162346 & -5.144363 & 2.01 \\
\hline GARCH $(1,1)$ & -5.159971 & -5.138390 & 1.98 \\
\hline GARCH $(1,1)$ & -5.160288 & -5.138708 & 1.97 \\
\hline GARCH $(1,1)$ & -5.15550 & -5.130373 & 1.99 \\
\hline
\end{tabular}

Table 4, the selection order of before issued

\begin{tabular}{|l|l|l|l|}
\hline & AIC & SC & DW \\
\hline GARCH $(1,1)$ & -5.676784 & -5.639194 & 1.99 \\
\hline GARCH $(1,1)$ & -5.675588 & -5.631733 & 1.99 \\
\hline GARCH(1,1) & -5.669759 & -5.635904 & 1.99 \\
\hline GARCH $(1,1)$ & -5.661220 & -5.631100 & 2.00 \\
\hline
\end{tabular}

Table 5, the selection order of after issued

\begin{tabular}{|l|l|l|l|}
\hline & AIC & SC & DW \\
\hline GARCH $(1,1)$ & -4.669865 & -4.626010 & 1.98 \\
\hline GARCH $(1,1)$ & -4.654424 & -4.604304 & 2.03 \\
\hline GARCH(1,1) & -4.656553 & -4.606433 & 2.04 \\
\hline GARCH $(1,1)$ & -4.652440 & -4.596055 & 2.02 \\
\hline
\end{tabular}

Establishment and analysis of the Model

What show in table 3 , table 4 and table 5 is that $\operatorname{GARCH}(1,1)$ model should be respectively established for research whether total sample interval or before and after the stock index futures. And Table 6 as well as Table 7 are the results of the model estimate of each sample intervals.

Table 6 lists the parameters of the total whole sample $\operatorname{GARCH}(1,1)$ model estimated. Wherein the coefficient of $\mathrm{D}$ is negative, suggesting the introduction of stock index futures reduced the volatility of the spot market, although this effect is not significant.

Table 6 , GARCH(1,1) model estimation results of the total samples

\begin{tabular}{|c|l|c|c|c|}
\hline & $a_{0}$ & $a_{1}$ & $\beta_{1}$ & $\varphi$ \\
\hline$R$ & $7.48 \mathrm{E}-06$ & 0.034522 & 0.950825 & $-4.3 \mathrm{E}-06$ \\
\hline
\end{tabular}

Table 7, model estimation results of before and after the launch of stock index futures

\begin{tabular}{|c|c|c|c|c|}
\hline & $\mathrm{a}_{0}$ & $\mathrm{a}_{1}$ & $\beta_{1}$ & $\varphi$ \\
\hline $\mathrm{R} 1$ & $4.00 \mathrm{E}-06$ & 0.062432 & 0.931463 & $0.993895<1$ \\
\hline $\mathrm{R} 2$ & $3.90 \mathrm{E}-05$ & 0.011054 & 0.790123 & $0.801177<1$ \\
\hline
\end{tabular}

A comparative research should be carried between before Stock Index Futures issued and after the introduction of the Stock Index Futures. Table 7 is the GARCH $(1,1)$ estimation results of the two subinterval return. By observing the table 7 can found that the value of coefficient $D$ after the HS300 stock index futures introduced(0.011054) is less than before it issued(0.062432), showing the current variance has weakened the impact on the noise of pre-market or the degree of response 
to information.

\section{Conclusion}

This article studies the effects of the stock index futures on the spot market volatility of China, through using GARCH(1,1) model. The empirical results show that the introduction of HS300 stock index futures has weaken the volatility of the spot market in spite of its small; By comparing the GARCH $(1,1)$ estimation results of the two subinterval return can learn that the influence of "noise" on the spot market volatility and lasting effects are reduced after the introduction of the HS300 index futures. So we can learn that when the introduction of stock index futures, the transmission of the spot market information get faster, showing that futures trading can indeed improve the speed of information which is flowing into the spot market, thus to develop the function of price discovery.

Therefore, only under a good market condition, stock index futures can develop stably and healthily, and its functions of price discovery, hedging risk and asset allocation can be promoted . So regulatory should intensify supervision, financial institutions should focus on trading risk prevention mechanisms, as well as investors should thoroughly learn the knowledge of stock index futures.

\section{Acknowledgement}

This article is the research result of Beijing major subject and modern circulation development, innovation of Beijing Wuzi University, and excellent teaching team in Beijing.

\section{References}

[1]Pierluigi Bologna, Does the introduction of stock index futures effectively reduce stock market volatility? the 'futures effect' immediate? evidence from the Italian stock exchange using GARCH, J. Applied Financial Economies, 12(2002) 183- 192.

[2]Panayiotis Alexakis, On the effect of index futures trading on stock market volatility, J. International Research Journal of Finance and Economics, 9(2007) 7-20.

[3]Li zhuo, A study of the impact of stock index futures on the cash market, D. The master's thesis of jilin university, 2006.

[4]Xing tiancai, Zhang ge, An empirical research of stock index futures effected on linkage efficiency of the spot market-analysis based on the simulation of the HS300 index futures data, J. Research on Financial and Economic Issues. 4(2010) 48-54.

[5]Liu fenggen, Wang xiaofang, The relationship between stock index futures and the volatility of stock market, J. Finance and Trade Research. 3(2008) 93-94.

[6]Zhao xiangqin, Deng yujing, Yan hu, The analysis of HS300 index futures effect on the volatility of the spot market, J. Productivity Research,7(2012) 80-82.

[7]Qiao gaoxiu, Liu qiang, Volatility and volatility spillovers in the CSI 300 index and futures market, J. Investment Research, 8(2012) 132-144.

[8]Hua renhai, Zhang peng, The impact of introducing index futures trading on volatility of the underlying asset in China stock market:An empirical analysis with Markov-Switching -GARCH model, J. South China Journal of Economics, 10(2012) 115-122.

[9]Xie lei, Wang yeheng, Empirical study on influence of stock index futures on stock spot market 
fluctuation, J. Technology Economics, 3(2010) 73-78.

[10]Hu qiuling, Zhang sufeng, Research on price discovery and volatility spillovers of China Hu-Shen 300 stock index futures, J. Journal of Beijing institute of technology, 6(2002), 77-82. 